\title{
ОТРАСЛЕВЫЕ ОСОБЕННОСТИ ЭЛЕКТРОЭНЕРГЕТИКИ И ИХ ВЛИЯНИЕ НА ОРГАНИЗАЦИЮ УЧЕТА ЗАТРАТ
}

\section{(c) 2021 Малиновская Н. В.}

доктор экономических наук, профессор Департамента аудита и корпоративной отчетности Финансовый университет при Правительстве Российской Федерации, Россия, Москва

E-mail: nvmali@mail.ru

В статье рассмотрена современная структура электроэнергетики - одной из стратегических отраслей экономики России, обеспечивающей электрической и тепловой энергией, как внутренние потребности страны, так и осуществляющей поставку электроэнергии на экспорт в европейские страны и СНГ. Современная структура электроэнергетики сложилась в результате реформирования отрасли, начатого в начале 2000-х годов. Каждый сегмент энергетического бизнеса имеет свои специфические особенности, которые необходимо принимать во внимание при организации бухгалтерского и управленческого учета затрат. В статье обобщены отраслевые особенности, влияющие на организацию учета затрат и калькулирование себестоимости продукции и услуг, отражающие современные тенденции развития электроэнергетики.

Ключевые слова: электроэнергетика, сегменты электроэнергетики, отраслевые особенности, учет затрат, калькулирование себестоимости.

Стратегической целью реформирования электроэнергетики, которое началось в начале 2000-х годов [1], являлось создание конкурентной рыночной среды, полноценного оптового рынка и эффективных розничных рынков электроэнергии для обеспечения надежного энергоснабжения потребителей различных типов. Реструктуризация отрасли привела к созданию новой ее структуры (рис.1).

Новая структура электроэнергетики значительно упростила формирование системы раздельного учета затрат и объема выпускаемой продукции (услуг) в натурально-стоимостном выражении по видам деятельности:

- производство электрической энергии (мощности);

- производство тепловой энергии;

- услуги по передаче электрической энергии (мощности);

- услуги по передаче тепловой энергии;

- деятельность по оперативно - диспетчерскому управлению;

- сбыт (реализация) электрической энергии;

- сбыт (реализация) тепловой энергии.

Появилась реальная возможность контролировать затраты и эффективность деятельности энергетических компаний, развивать конкурентную рыночную среду, снижать энергетические потери, удовлетворять потребности «эко- номики и населения страны в электрической энергии (мощности) по доступным конкурентоспособным ценам, обеспечивающим окупаемость инвестиций в электроэнергетику» [3].

В настоящее время генерация электрической энергии осуществляется электростанциями различного типа в зависимости от видов источников первичной энергии, используемых для производства электрической энергии:

- тепловыми электростанциями (ТЭС), источники энергии - газ (природный, попутный нефтяной), мазут, уголь, торф, дизельное топливо;

- атомными электростанциями (АЭС), источник энергии - ядерное топливо;

- гидроэлектростанциями (ГЭС), источник энергии - гидроресурсы;

- электростанции на возобновляемых источниках энергии (ВИЭ), источники энергии ветер, солнце, приливы и отливы, энергия земных недр и др.

Динамика выработки электроэнергии за 2017-2020 гг. в разрезе типов электростанций представлена на рисунке 2 .

Таким образом, несмотря на то, что доля нетопливных источников электрической энергии (АЭС+ГЭС+ВИЭ) в структуре производства электрической энергии постоянно увеличивается (в 2017 г. она составляла 36,4\%, в 2018 г. - 36,5\%, в 2019 г. $-37,1 \%$, в 2020 г. $-40,7 \%)$, для россий- 


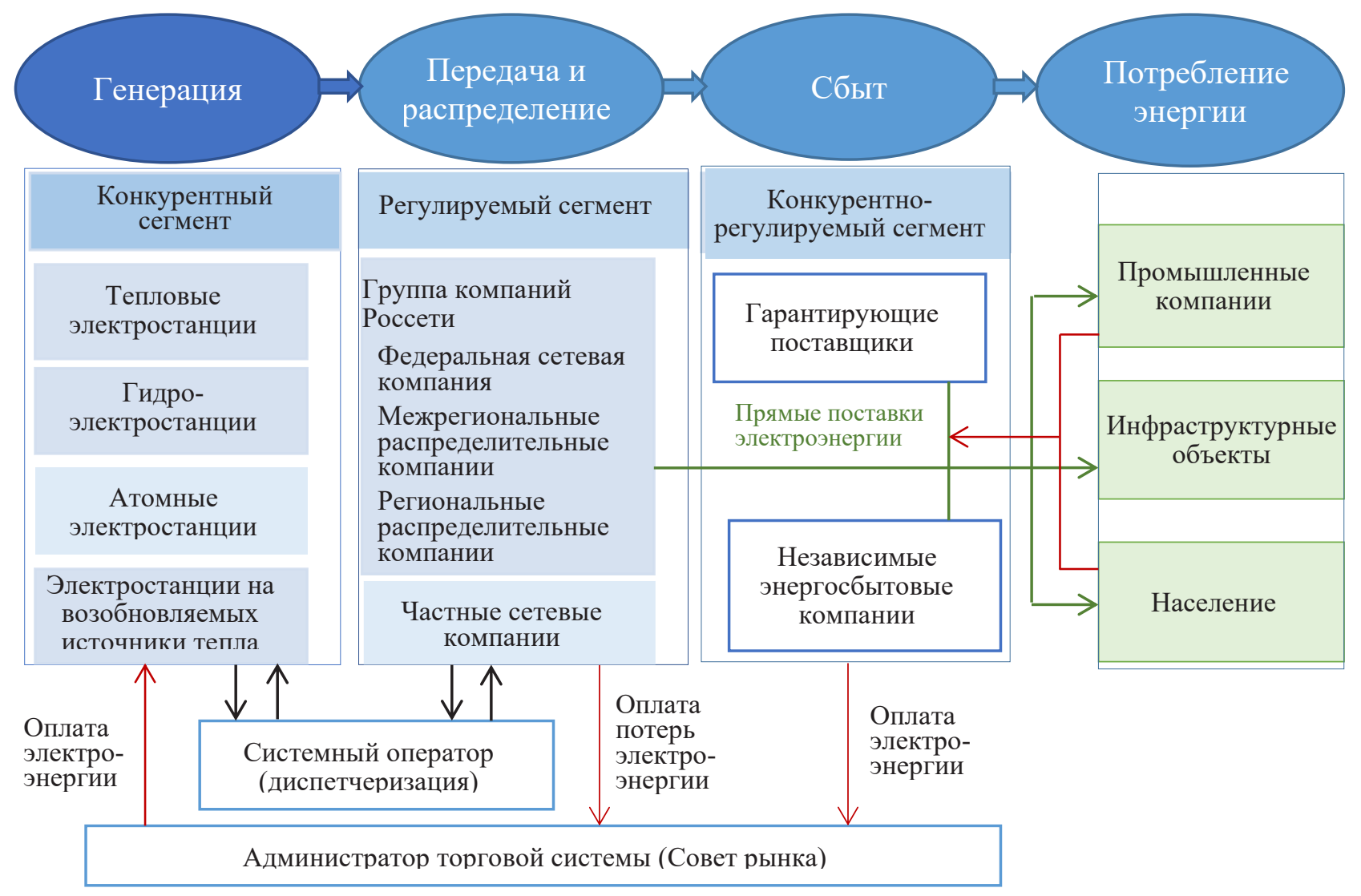

Рисунок 1. Структура электроэнергетики и место Группы Россети в ней Источник: составлено по материалам [2].

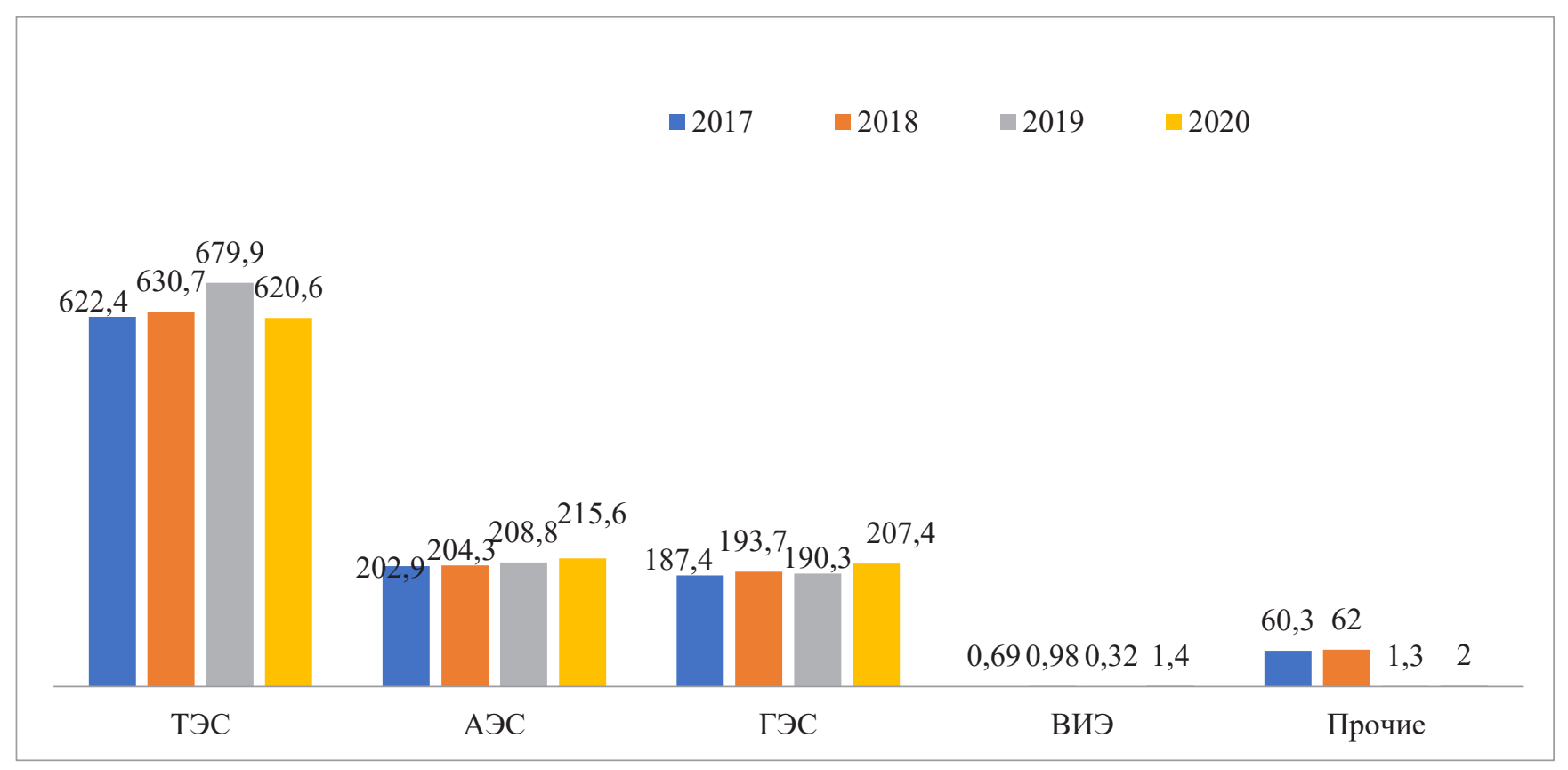

Рисунок 2. Динамика выработки электроэнергии за 2017-2020 гг., млрд. кВтч. Источник: составлено по материалам Минэнерго и Системного оператора Единой энергетической системы [4] (прочие - электростанций промышленных предприятий). 
ской электроэнергетики характерно доминирование генерации электроэнергии тепловыми электростанциями с использованием источников топлива на основе углеродного сырья. При этом доля газа в структуре топливообеспечения электростанций (без учета котельных) зоны централизованного электроснабжения составила в 2018 г. 74,6\%, доля угля 24,3\%.

На рисунке 3 представлена динамика доли затрат на топливо в составе операционных расходов крупнейших российских генерирующих электроэнергию компаний.

Как видно из рисунка 3, в структуре затрат ТЭС затраты на топливо составляют свыше 50\%, поэтому именно на управлении затратами на топливо следует сосредоточить свое внимание генерирующим электроэнергию компаниям с целью достижения стратегических параметров, закрепленных в Энергетической стратегии Российской Федерации на период до 2035 года [8]. Согласно новой Энергетической стратегии удельный расход топлива на отпуск электрической энергии должен составить к 2024 году 285,4 г у.т./кВт·ч; к 2035 году 255,6 г у.т./кВт·ч, в то время как в 2018 году он составлял 309,8 г у.т./кВт.ч.

Следует отметить, что процессы производства и потребления электроэнергии и теплоэнергии происходят одновременно, в этой связи на энергетических предприятиях отсутствует незавершенное производство. Однако потре- бление электро- и теплоэнергии осуществляется неравномерно в течение различных периодов (года, месяца. суток), поэтому необходим резерв мощности на электростанциях и сетях для обеспечения бесперебойного снабжения потребителей электроэнергией и теплом. В 2018 году среднее значение коэффициента использования установленной мощности (КИУМ) по тепловым станциям ЕЭС России составило 46,5\%, в 2019 г.45,7, в 2020 г.- 41,3\% [3]. Объем производства электроэнергии зависит исключительно от потребностей потребителей и диспетчируется системным оператором.

Особенности деятельности сетевых компаний обусловлены большой протяженностью линий электропередачи (ЛЭП)* разного класса напряжения, наличием большого количества подстанций (ПС) разной трансформаторной мощности, широкой географией присутствия, ведением нескольких видов деятельности (передача и распределение электрической энергии, технологическое присоединение потребителей к электрической сети, эксплуатация электрических сетей и др.), требующих дифференциации затрат между ними. Передача электроэнергии на большие расстояния неизбежно ведет к ее потерям. Так, например, уровень потерь электрической энергии в ПАО «Россети» в 2018 г. составил 8,95\% (в 2017 г. 9,22\%). В то же время необходимо бесперебойно снабжать электроэнергией потребителей.

* Протяженность линий электропередачи Группы компаний «Россети» - крупнейшей системообразующей электросетевая компания - составила в 2018 г. 2,35 млн. км. Группа компаний «Россети» функционирует в 80 субъектах Российской Федерации.

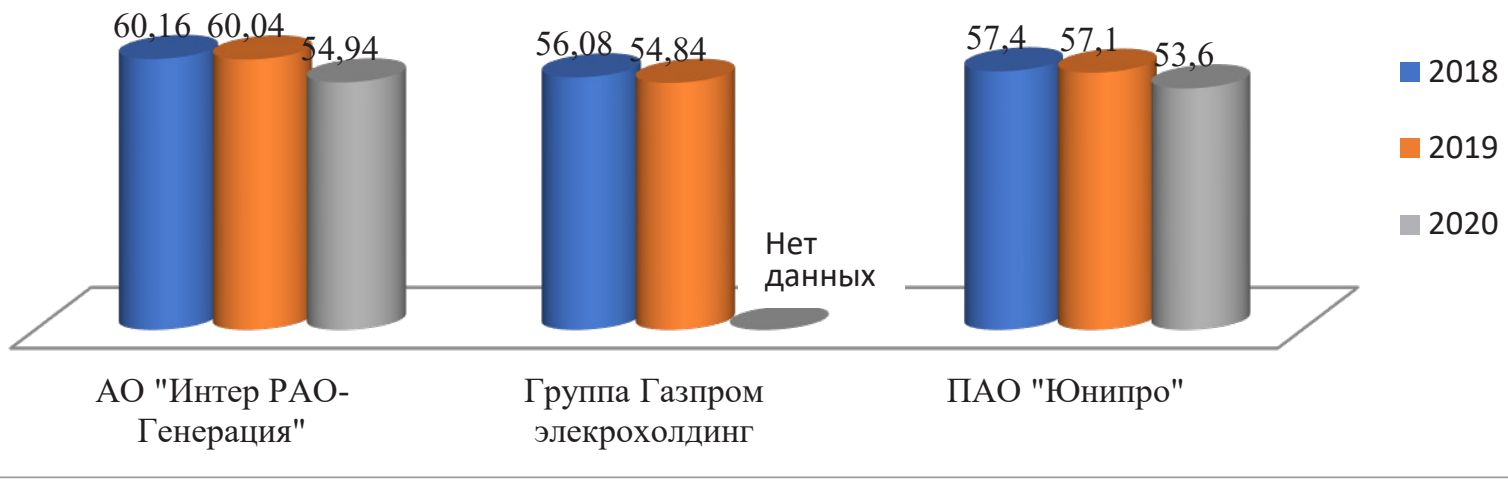

Рисунок 3. Доля затрат на топливо в составе операционных расходов при генерации электроэнергии,\%. Источник: составлено по материалам [5-7]. 
Поскольку электроэнергетика является регулируемым видом деятельности [9], государство устанавливает тарифы и цены на электрическую энергию на розничном (потребительском) рынке [10], на электрическую энергию (мощность), произведенную генерирующими объектами ВИЭ и приобретаемую в целях компенсации потерь в электрических сетях [11], на тепловую энергию (мощность) [12], на услуги по передаче энергии. В соответствии с законодательством только объемы электроэнергии и мощности, произведенной сверх установленных для каждого продавца на оптовом рынке объемов и законтрактованных по регулируемым договорам для поставки населению и приравненным к нему категориям потребителей, продаются по свободным ценам оптового рынка.

Законодательно установленные методы регулирования цен (тарифов) в электроэнергетике представлены на рисунке 4.

При использовании метода экономически обоснованных расходов (затрат) затраты, связанные с производством и реализацией продукции (услуг) по регулируемым видам деятельности, классифицируются в разрезе следующих элементов:

1) расходы на топливо;

2) расходы на покупку электрической и тепловой энергии (мощности);

3) расходы на оплату услуг, оказываемых организациями, осуществляющими регулируемую деятельность;

4) расходы на сырье и материалы (на производственные и хозяйственные нужды);

5) расходы на ремонт основных средств;

6) расходы на оплату труда и страховые взносы;
7) расходы на амортизацию основных средств и нематериальных активов,

8) прочие расходы.

При использовании метода долгосрочной индексации необходимой валовой выручки регулирующим органом устанавливается базовый уровень подконтрольных расходов, индекс эффективности и коэффициент эластичности подконтрольных расходов. Таким образом, расходы, связанные с производством и реализацией продукции (услуг), разделяются на подконтрольные расходы, на рост которых регулируемая компания может оказать влияние, и неподконтрольные ей расходы.

Рассмотренные методы создают основу для единообразного подхода к классификации затрат энергетических компаний.

Общемировые тенденции, направленные на снижение негативного воздействия отдельных видов энергетических ресурсов, используемых в производстве электрической и тепловой энергии, на окружающую среду требуют более активного развития ВИЭ. По прогнозу Международного энергетического агентства к 2040 г. доля электроэнергии, произведенной генерирующими объектами ВИЭ, составит 20-35\%.

Перспективы развития электроэнергетики также связывают с развитием технологий накопления электроэнергии, обеспечивающих управляемость выдачи мощности от ВИЭ в энергосистему и снижение инвестиции в резервные мощности; развитием технологии «умных сетей» (smart grid), интеллектуальных систем учета электрической энергии (мощности), переходом потребителей к активным моделям поведения, и, как результат, созданием интеллектуальной электроэнергетической системы (ИЭС)*.

* Интеллектуальная система учета электрической энергии (мощности) - система удаленного сбора, обработки, передачи показаний приборов учета электрической энергии в режиме реального времени.

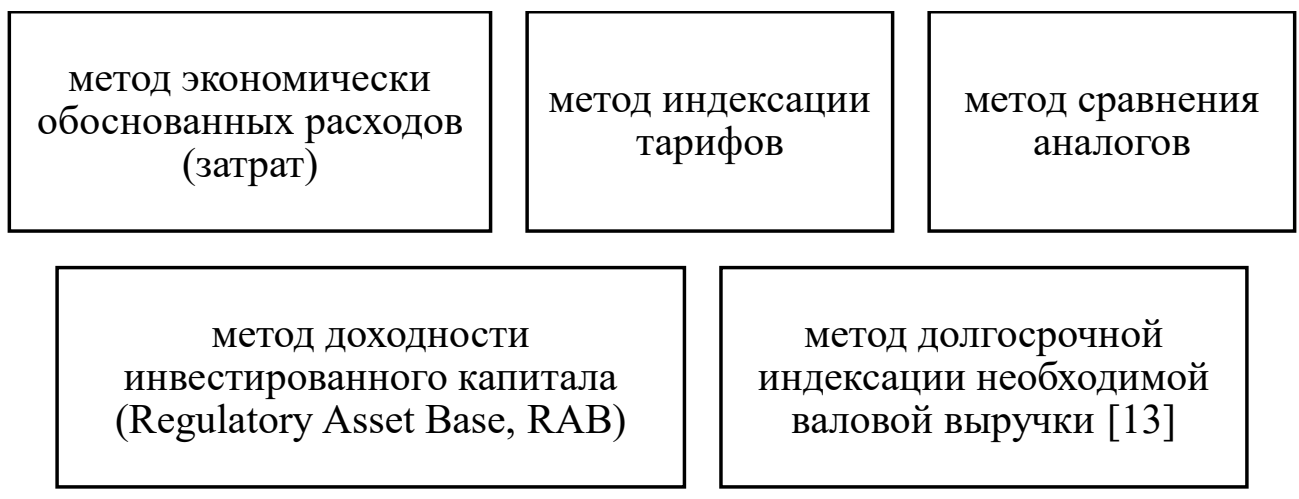

Рисунок 4. Методы регулирования цен (тарифов) в электроэнергетике 
В настоящее время в энергетике уже есть подстанции, где до 80\% информации обрабатывается в автоматическом режиме. С развитием технологий передачи и хранения данных датчики перестанут быть только измерителями, а станут оцифровывать, анализировать и передавать обработанную информацию при помощи беспроводных технологий на верхний уровень. Внедрение цифровых двойников оборудования и систем прогнозирования позволит на основе цифровой диагностики спрогнозировать воз- можные сбои в работе оборудования и своевременно их предупредить.

Таким образом, на организацию учета затрат в электроэнергетике оказывает влияние ряд факторов, представленных в таблице 1.

Учет данных факторов при организации бухгалтерского и управленческого учета затрат позволит реализовать те новые задачи, которые поставлены перед энергетическими компаниями в Энергетической стратегии России на период до 2035 года.

Таблица 1. Факторы, влияющие на организацию учета затрат и калькулирование себестоимости в электроэнергетике

\begin{tabular}{|c|c|c|}
\hline Факторы & Содержание & $\begin{array}{c}\text { Влияние на организацию учета затрат и } \\
\text { калькулирование }\end{array}$ \\
\hline $\begin{array}{l}\text { Либерализация рын- } \\
\text { ка электро-энергии }\end{array}$ & $\begin{array}{l}\text { Из монопольной вертикально- интегри- } \\
\text { рованной структуры выделены отдельные } \\
\text { направления бизнеса: генерация, передача } \\
\text { и распределение, сбыт. } \\
\text { Созданы оптовый рынок электроэнергии } \\
\text { и мощности (ОРЭМ) и розничный рынок } \\
\text { электроэнергии и мощности (РРЭМ) }\end{array}$ & $\begin{array}{l}\text { Учет затрат в разрезе электростанций, } \\
\text { энергоблоков, по видам деятельности и } \\
\text { структурным подразделениям. При- } \\
\text { менение попроцессного метода учета } \\
\text { затрат и калькулирования себестои- } \\
\text { мости электроэнергии, позаказного } \\
\text { метода учета затрат и калькулирования } \\
\text { себестоимости услуг технологического } \\
\text { присоединения }\end{array}$ \\
\hline Развитие ВИЭ & $\begin{array}{l}\text { Возобновляемые источники энергии ока- } \\
\text { зывают меньшее негативное влияние на } \\
\text { окружающую среду }\end{array}$ & $\begin{array}{l}\text { Изменение структуры затрат за счет } \\
\text { отсутствия затрат на топливо. }\end{array}$ \\
\hline $\begin{array}{l}\text { Регулирование } \\
\text { деятельности }\end{array}$ & $\begin{array}{l}\text { Государством устанавливаются тарифы на } \\
\text { электрическую и тепловую энергию, услуги } \\
\text { по передаче, распределению и сбыту, в } \\
\text { том числе на основе метода экономически } \\
\text { обоснованных затрат. }\end{array}$ & $\begin{array}{l}\text { Возможность применения нормативно- } \\
\text { го метода учет затрат и калькулирова- } \\
\text { ния себестоимости. }\end{array}$ \\
\hline Цифровизация & $\begin{array}{l}\text { Данные в цифровой форме становятся } \\
\text { ключевым фактором производства }\end{array}$ & $\begin{array}{l}\text { Использование номенклатуры ста- } \\
\text { тей затрат, утвержденных в формах } \\
\text { для включения в государственную } \\
\text { информационную систему топливно- } \\
\text { энергетического комплекса (ГИС ТЭК) } \\
\text { [14]. }\end{array}$ \\
\hline
\end{tabular}

\section{Библиографический список}

1. Постановление Правительства РФ от 11 июля 2001 г. № 526 «О реформировании электроэнергетики Российской Федерации». URL: http://www.consultant.ru

2. ПАО «Россети». Годовой отчет 2019. URL: http://www.rustocks.com/put.phtml/ MRKH_2019_RUS.pdf

3. Энергетическая стратегия России на период до 2030 года. Утверждена распоряжением Правительства Российской Федерации от 13 ноября 2009 г. № 1715-p. URL: http://www.consultant.ru

4. Системный оператор Единой энергетической системы. Отчет о функционировании ЕЭС России в 2020 году. URL: https://www.so-ups.ru/fileadmin/files/ company/reports/disclosure/2021/ups_rep2020.pdf

5. Аудиторское заключение независимого аудитора о бухгалтерской (финансовой) отчетности АО «Интер РАO - Электрогенерация» за 2020 год. URL: https://irao-generation.ru/upload/iblock/4cc/auditorskoezaklyuchenie-ehlektrogeneraciya-rsbu-2020-final_.pdf

6. Отчет об устойчивом развитии производственных компаний Группы Газпром энергохолдинг за 20182019 гг. URL: https://energoholding.gazprom.ru/d/textpage/5c/92/ 18-19-sustainability-geh-report-rus.pdf

7. ПАО «Юнипро». Годовой отчет 2020 г. URL: https://unipro.energy/shareholders/disclosure/annual_reports/ 
8. Энергетическая стратегия России на период до 2035 года. Утверждена распоряжением Правительства Российской Федерации от 09 июня 2020 г. № 1523-p. URL: http://static.government.ru/media/files/w4sigFOiDjGV DYT4IgsApssm6mZRb7wx.pdf

9. Постановление Правительства РФ от 29 декабря 2011 года № 1178 «О ценообразовании в области регулируемых цен (тарифов) в электроэнергетике». URL: http://docs.cntd.ru/document/902323702.

10. Приказ ФСТ России от 06.08.2004 № 20-э/2 «Об утверждении Методических указаний по расчету регулируемых тарифов и цен на электрическую (тепловую) энергию на розничном (потребительском) pынке». URL: http://docs.cntd.ru/document/901908404

11. Приказ ФАС России от 30.09.2015 № 900/15 «Об утверждении Методических указаний по установлению цен (тарифов) и (или) предельных (минимальных и (или) максимальных) уровней цен (тарифов) на электрическую энергию (мощность), произведенную на функционирующих на основе использования возобновляемых источников энергии квалифицированных генерирующих объектах и приобретаемую в целях компенсации потерь в электрических сетях». URL: http://docs.cntd.ru/document/420309978

12. Приказ ФСТ России от 13.06.2013 № 760-э «Об утверждении Методических указаний по расчету регулируемых цен (тарифов) в сфере теплоснабжения». URL: http://docs.cntd.ru/document/499034124

13. Приказ ФСТ от 17.02.2012 № 98-э «Об утверждении Методических указаний по расчету тарифов на услуги по передаче электрической энергии, устанавливаемых с применением метода долгосрочной индексации необходимой валовой выручки». URL: http://docs.cntd.ru/document/902331695

14. Приказ Минэнерго России от 16.08.2019 № 865 «Об утверждении форм представления в обязательном порядке юридическими лицами и индивидуальными предпринимателями информации для включения в сегмент в области электроэнергетики, теплоэнергетики и возобновляемых источников энергии государственной информационной системы топливно-энергетического комплекса и требований к заполнению этих форм и о внесении изменений в приказ Минэнерго России от 23 июля 2012 г. № 340 «Об утверждении перечня представляемой субъектами электроэнергетики информации, форм и порядка ее заполнения». URL: http://docs.cntd.ru/document/542653581 